\title{
ВЗАИМОДЕЙСТВИЕ ОРГАНОВ ГОСУДАРСТВЕННОЙ И МУНИЦИПАЛЬНОЙ ВЛАСТИ ПРИ УПРАВЛЕНИИ СТРОИТЕЛЬСТВОМ И ЭКСПЛУАТАЦИИ АВТОМОБИЛЬНЫХ ДОРОГ
}

\author{
А. П. Панков \\ Московский гуманитарный университет
}

Аннотация: В статье рассматривается организация взаимодействия органов федеральной и муниципальной власти при управлении строительством и эксплуатации автомобильных дорог. Излагаются теоретические и практические проблемы, складывающиеся в области управления строительством и эксплуатации автомобильных дорог в Российской Федерации.

Ключевые слова: автомобильная дорога; дорожная деятельность; государственное и муниципальное управление

\section{INTERACTION OF STATE AND MUNICIPAL AUTHORITIES IN THE MANAGEMENT OF THE CONSTRUCTION AND OPERATION OF ROADS}

\author{
A. P. Pankov \\ Moscow University for the Humanities
}

\begin{abstract}
The article deals with the organization of interaction between the federal and municipal authorities in the management of the construction and operation of roads. The author states theoretical and practical problems developing in the field of the management of the construction and operation of roads in the Russian Federation.
\end{abstract}

Keywords: road; road activity; state and municipal management

Проблема российских дорог не теряет своей актуальности на протяжении многих лет, тема окружена многочисленными шутками, остротами и крылатыми выражениями. Тем не менее, говорить на эту тему просто необходимо, но только изначально нацелившись на поиск решения.

Автомобильные дороги являются важнейшим звеном общей транспортной системы государства. От состояния автомобильных дорог во многом зависит развитие административных центров, регионов и всей страны в целом. 
Понятие «автомобильная дорога» включает в себя целый комплекс инженерных сооружений, которые предназначены для обеспечения круглогодичного, непрерывного, удобного и безопасного движения автомобилей в любое время года и в любых условиях погоды. Для этого рассчитывается нагрузка и для определенных участков устанавливаются разрешенные скорости.

Строительство и эксплуатация автомобильных дорог в России регулируется Федеральным законом от 08.11.2007 № 257-ФЗ (ред. от 03.08.2018) «Об автомобильных дорогах и о дорожной деятельности в Российской Федерации и о внесении изменений в отдельные законодательные акты Российской Федерации».

Согласно нормам данного закона, вся совокупность автомобильных дорог в России распределена между различными собственниками.

В Российской Федерации автомобильные дороги находятся в федеральной, региональной или муниципальной собственности. Кроме этого дороги могут быть собственностью физических или юридических лиц.

Автомобильные дороги, которые являются федеральной собственностью, включены в перечень автомобильных дорог общего пользования федерального значения или перечень автомобильных дорог необщего пользования федерального значения. Данные перечни утверждаются соответственно Правительством России или уполномоченными федеральными органами исполнительной власти.

Те дороги, которые принадлежат субъекту Российской Федерации, включаются в перечень автомобильных дорог общего пользования регионального, межмуниципального значения либо перечень автомобильных дорог не общего пользования регионального или межмуниципального значения. Такой перечень утверждается высшим исполнительным органом государственной власти субъекта Российской Федерации.

Собственностью муниципального района являются автомобильные дороги общего и не общего пользования, которые соединяют населенные пункты в границах муниципального района. Из данного перечня исключаются автомобильные дороги федерального, регионального или межмуниципального значения, а также частные автомобильные дороги.

Протяженность дорожной сети общего пользования в нашей стране составляет 1,4 млн километров. Дороги федерального значения из них составляют всего лишь 51 тыс. километров. Дорог регионального значения почти в десять раз больше - 503 тыс. километров, еще внушительнее протяженность местных дорог - 842 тыс. километров. Как мы видим, федеральные дороги составляют только 3,5\% от общего массива. (Как повысить качество ..., 2016: Электр. ресурс).

За последние два года соответствие нормативным требованиям федеральных трасс выросло с 45\% до 64\%. Ситуация с региональными дорогами гораздо печальней: за это же время положительная динамика составила $1 \%$. Учитывая нынешнее состояние региональных дорог (в хорошем состоянии 
Научные труды Московского гуманитарного университета

2019 № 1

находится порядка 39\% от общего количества), нетрудно сосчитать, что мы дождемся нормативного состояния всего полотна через 120 лет (там же).

Именно поэтому вопрос взаимодействия органов государственной и муниципальной власти при управлении строительством и эксплуатации автомобильных дорог сегодня стоит особенно остро.

Согласно нормам отечественного законодательства, деятельность по строительств, ремонту и содержанию автомобильных дорого называется - дорожной деятельностью.

Содержание автомобильной дороги - комплекс работ по поддержанию надлежащего технического состояния автомобильной дороги, оценке ее технического состояния, а также по организации и обеспечению безопасности дорожного движения (Добросердова, 2017).

Осуществление дорожной деятельности в отношении автомобильных дорог федерального значения обеспечивается:

- федеральным органом исполнительной власти, который осуществляет функции по оказанию государственных услуг и управлению государственным имуществом в сфере дорожного хозяйства. Таким органом является Федеральное дорожное агентство (Росавтодор), находящимся в ведении Министерства транспорта РФ;

- Государственной компанией «Российские автомобильные дороги», но только в том случае если автомобильная дорога передана в доверительное управление.

Осуществление дорожной деятельности в отношении автомобильных дорог регионального или межмуниципального значения обеспечивается уполномоченными органами исполнительной власти субъектов Российской Федерации. Такими органами являются департаменты дорожного хозяйства, департаменты автомобильных дорог областей, краев, республик и округов. Департаменты осуществляет право оперативного управления в отношении региональных дорог, закрепленных за ними правительствами регионов.

Дорожная деятельность в отношении автомобильных дорог, являющихся собственностью муниципалитетов и городских округов обеспечивается уполномоченными органами местного самоуправления. В различных муниципальных образованиях они могут иметь разные наименования: департаменты транспорта, дорог и благоустройства; управления по благоустройству; отделы жилищно-коммунального хозяйства; отделы транспорта, связи и благоустройства и т. д.

Ремонт и содержание региональных автомобильных дорог и дорог местного значения осуществляется дорожными подразделениями (ДРСУ, ДЭУ и т. д.), а также привлекаемыми в отдельных случаях на основе конкурсов (подрядных торгов) другими специализированными организациями.

За дорожными организациями закрепляются автомобильные дороги по линейному или территориальному принципу. Протяженность участков дорог, которые обслуживаются дорожными организациями, устанавлива- 
ется в зависимости от категории дороги, климатических особенностей и типов покрытий, начертания сети автомобильных дорог и т. п.

Ремонт и содержание федеральных автомобильных дорог осуществляется федеральными казенными учреждениями - управлениями автомобильных дорог, федеральными государственными унитарными дорожно эксплуатационными предприятиями, дорожными организациями других форм собственности.

Существующая в настоящий момент схема взаимодействия государственных и муниципальных органов власти не достаточно эффективна. Автодороги регионального и муниципального уровня ремонтируются только за счет средств властей субъектов. В результате в удовлетворительном состоянии находится только порядка половины трасс.

Минтранс предлагает в 2019 г. оплатить 30\% затрат на ремонт региональных дорог и в последующие годы увеличивать долю вплоть до 50\%. Оставшуюся долю должны будут вносить регионы из своих бюджетов.

Несмотря на то, что из федерального бюджета в соответствии с законодательством выделяются средства на ремонт только федеральных трасс, в рамках правительственных программ регионам выделят до 17\% от необходимого объема средств на дороги уровня субъектов.

Протяженность региональных дорог в России, по данным Росстата, превышает 510 тысяч километров. Нормативам же соответствует только 52,5\% из них, по информации Росавтодора. Какая сумма потребуется для софинансирования ремонта региональных и муниципальных дорог из федерального бюджета, пока неизвестно. По оценке председателя межрегиональной общественной организации «Движение автомобилистов» Армена Оганесяна, речь может идти о сотнях миллиардов рублей (Добросердова, 2017).

Власти регионов в настоящее время составляют карту дорог, которые войдут в нацпроект. По мнению эксперта, в идеале доля софинансирования ремонта дорог из федерального бюджета должна составлять не менее 7080\%. Обычная практика сейчас: если местные власти находят деньги на ремонт дорог, то они экономят на материалах. Это приводит к тому, что через пару месяцев после сдачи работ появляются трещины на асфальте.

На этот насущный вопрос на заседании правительства частично ответил министр транспорта Максим Юрьевич Соколов. Он предложил увеличить долю акцизов, направляемых в региональные дорожные фонды до 88\%, а с 2017 г. - до 100\%. Кроме того, были заявлены и другие способы увеличения объемов региональных дорожных фондов (Нехайчук, 2015: Электр. ресурс)

Среди них межбюджетные трансферты. Еще одна мера, которая активно обсуждается властными структурами - «покрасить» средства дорожных фондов, чтобы они не могли быть потрачены на другие цели. Это предложение выглядит наиболее актуальным.

Действительно, даже увеличение объемов региональных фондов будет 
бесполезным, если местные власти используют эти деньги на что-то другое. Дмитрий Медведев, в частности, отметил, что необходимо более жестко разбираться с подрядчиками, которые не соблюдают нормативы, «напускать» на них проверяющие органы и, конечно же, расставаться с ними.

К сожалению, ничего не было сказано про устаревшие нормативы. Очевидно, что дорожное строительство не может быть эффективным, если применяются правила, установленные еще во времена СССР.

Согласно Global Competitiveness Report 2015-2016 гг., Российские дороги на международной арене поднялись в рейтинге за последние годы на 13 позиций: со 136-го места на 123-е. Это можно назвать неплохим результатом.

Правда, следует помнить, как составляется данный рейтинг: он готовится на основании оценок бизнесменов. Серьезный анализ здесь не проводится, по сути, все базируется на субъективных мнениях.

Наше сознание довольно инертно, многочисленные ментальные традиции по осмеиванию отечественных дорог, безусловно, влияют на многих сильнее, чем окружающая реальность.

Однако нельзя сбрасывать данный показатель со счетов, в той или иной мере он отражает действительность. Правда, нужны и серьезные рейтинги, создаваемые на основе глубокой аналитики. Более того, они необходимы. Так российские власти и специалисты смогли бы объективнее и полнее оценивать состояние отечественных дорог.

\section{СПИСОК ЛИТЕРАТУРЫ}

Добросердова, Е. А. (2017) Совершенствование системы управления дорожного хозяйства муниципальных образований. СПб. : Питер. 124 с.

Как повысить качество региональных и муниципальных дорог (2016) [Электронный ресурс] // PolitRussia.com. URL: http://politrussia.com/ ekonomika/kak-povysit-kachestvo-577/ (дата обращения: 24.11.2018).

Нехайчук, Ю. (2015) Кто должен платить за строительство дорог в России [Электронный ресурс] // Ведомости. 3 декабря. URL: https://www. vedomosti.ru/realty/articles/2015/12/03/619431-kto-platit-dorog (дата обращения 21.11.2018 г.)

Дата поступления: 20.12.2018.

Панков Александр Павлович - студент 1 курса магистратуры, направление «Государственное и муниципальное управление (Управление муниципальным хозяйством)» Московского гуманитарного университета. Адрес: 111395, Россия, г. Москва, ул. Юности, д. 5. Тел.: + 7 (910) 483-78-90. Эл. адрес: 89036272372@mail.ru

Pankov Alexander Pavlovich, Graduate Student, programme of study «State and Municipal Management (Management of Municipal Economy)", Moscow University for the Humanities. Postal address: 5, Yunosti St., Moscow, Russian Federation, 111395. Tel.: +7 (910) 483-78-90. E-mail: 89036272372@mail.ru 


\section{Для цитирования:}

Панков А. П. Взаимодействие органов государственной и муниципальной власти при управлении строительством и эксплуатации автомобильных дорог [Электронный ресурс] // Научные труды Московского гуманитарного университета. 2019. № 1. URL: http://journals.mosgu.ru/trudy/article/view947 (дата обращения: дд.мм.гг.). DOI: 10.17805/trudy.2019.1.18 